\title{
Conversações
}

\section{Janice Caiafa*}

\section{RESUMO}

No transporte coletivo urbano gera-se um espaço muito singular de comunicação. São desconhecidos, completamente estranhos uns aos outros, que se deslocam lado a lado. Essas pessoas, que um destino comum reuniu ali, vão se observar, vão despertar para as presenças em torno, vão se falar? No meio tenso das viagens de ônibus no Rio de Janeiro, o isolamen. to, o namoro, as interpelações agressivas, e ainda as conversas de ocasião preenchem um quotidiano muito interessante. Este artigo explora as condiçōes da comunicaçāo nesse contexto, apontando e descrevendo algumas características da conversação nas viagens.

\section{ABSTRACT}

Public transportation in the cities involves a ven particular modality of communication. People who do not know each other are brought logethler and sit side by side while traveling across the city streets. Do these strangers, who happen to share a common destination, look around and notice the others? Do they talk? During the bus rides in Rio de Janeiro, isolation, flirts, violent approaches, and occasional conversations constitule an often tense and certainly eventful milieu. This article explores the conditions of communication in this context, individualing and describing the characteristics of conversation along the bus rides.

\footnotetext{
Janice Caiafa Doutora em antropologia pela Universidade de Cornell. E.U.A, com Pós-Doutorado pela City University of New York. É poetisa, professora da Escola de Comunicação da UFRJ e autora, entre outros, de Nosso Século XXI (Relume Dumará, 2000) e Jornadas Urbanas (FGV Editora, 2002).
} 


\section{Deslocar-se nas cidades}

No transporte coletivo urbano gera-se um espaço muito singular de comunicação. São desconhecidos, completamente estranhos. uns aos outros, que se deslocam - às vezes por um longo período - juntos, lado a lado. Podem também estar em situação de proximidade excessiva, nos veículos lotados. Essas pessoas, que um destino comum reuniu ali, vão se observar, vão despertar para as presenças em torno, vão se falar?

É característico das cidades esse tipo de risco ou oportunidade: defrontar-se com estranhos, circular em espaços coletivos, cruzando com desconhecidos, e em situações que freqüentemente não se podem prever. Nas ruas urbanas, quando elas se prestam à ocupação coletiva, experimentamos uma grande variedade de estímulos, incluindo uma diversidade humana que passa por nós e a que nos expomos. Na origem das cidades está um movimento, um deslocamento. A cidade se desenvolve como um ponto de atração para estrangeiros, outsiders de todo o tipo que vêm povoá-la, como demonstram Mumford (1961) e Braudel (1979). Diferente do grupo primário, ela oferece hospitalidade ao visitante estrangeiro — não para integrá-lo, mas para oferecer-lhe um lugar nessa mobilização (Caiafa, mimeo). Ela é mesmo o lugar mais propício para outsiders, por produzir um grande espaço de exterioridade em que se confrontam desconhecidos, em que se produz constantemente diversidade (Caiafa, 2002).

170 Uma primeira questão que se coloca é se os passantes vão se deixar afetar por essa diversidade em algum grau, se vai haver algum tipo de proximidade ou comunicação. Porque em alguns casos a heterogeneidade pode não produzir a diferença. Quando a variedade é passiva, não se transforma em experiência - é o caso do isolamento dos guetos e do espaço privatizado das cidades dependentes do automóvel (Caiafa, 1991 e 2003). Ali as situações tendem a ser previstas, o que acaba por reinstaurar os circuitos fechados dos meios familiares. O desconhecido é uma variedade muda, num espaço demarcado de identidades bem definidas.

Já por conduzir e distribuir as pessoas, por levá-las para longe de suas vizinhanças, o transporte coletivo efetua em algum grau uma dessegregação (Caiafa, 2002). Mesmo que não supere os códigos sociais que compartimentalizam, marcam, o transporte coletivo cria acesso, franqueia certas marcas e assim expõe as pessoas ao contato. E no meio mesmo que se produz durante as viagens, nos veículos coletivos em que nos transportamos nas cidades, podem-se criar oportunidades muito especiais para o confronto com a variedade urbana. Porque trata-se de um ambiente que cria uma pausa, faz sentar desconhecidos e os conduz pela cidade. Nesse caso também, os usos dessa oportunidade vão variar: em cada modalidade de transporte coletivo, em cada configuração urbana. $E$ vão variar as ocasiões de criatividade e de risco. 
No Rio de Janeiro os ônibus são o principal meio de transporte urbano. Muito freqüentados, eles são lugares cheios de acontecimentos, alguns deles podendo virar manchetes de jornais: acidentes, assaltos, incêndios criminosos. São empresas privadas que operam todas as linhas na cidade e que estabeleceram há muito tempo sua hegemonia. Observa-se ai portanto uma exploração muito acirrada do rodoviário, especifica do negócio do transporte como ele se apresenta nas malhas desse modelo privado e concentracionário. Características desse modelo acabam ressoando nas viagens, contribuindo para os atritos e se acrescentando ao problema da violência já grave na cidade (Caiafa, 2002). O resultado é que o meio do ônibus na cidade do Rio de Janeiro é um meio tenso, para passageiros e rodoviários, como atestam tantas entrevistas e minha própria experiência como usuária de ônibus.

Quando nos confrontamos com os desconhecidos ali, companheiros de viagem, já passamos provavelmente pela aventura de correr para alcançar o ônibus - que pode passar direto ou parar acolá do ponto mal assinalado e o motorista não ter a paciência de esperar. Já subimos o degrau altíssimo e pulamos de um só golpe para evitar cair no asfalto porque geralmente ou quase sempre o motorista dá a partida antes de o passageiro poder subir. Durante a viagem, existe o risco constante de cair porque desenvolveu-se ali um estilo de dirigir aos arrancos e frenqüentemente em alta velocidade. É preciso segurar firme - quem anda de ônibus sabe disso. Há muitos acidentes no interior dos ônibus, com idosos mas também com qualquer um. A maioria não é registrada porque parece que já se aceitou que esse é um risco para quem quer circular na cidade: o movimento é inseparável da queda ou do alto risco de uma queda. Uma usuária relata que viu uma senhora cair, levar "um tombo feio", num ônibus da linha 928 (Ramos-Marechal Hermes). Mas acrescentou que a culpa nesse caso não foi do motorista, embora ele estivesse correndo e tenha freado bruscamente, provocando o tombo. É que a senhora "se levantou muito antes do ponto, ai caiu". Machucou muito o braço, que ficou logo roxo. E não só ela reconheceu a imprudência ou a culpa da senhora, mas todo o ônibus, que passou a comentar e falar com ela.

Eu sou assim, se eu tô sentada, eu não levanto: eu levanto, puxo o sinal e continuo sentada. Quando vejo que ele começa, eu vejo que ele tá freando, eu vou e desço, porque eu já sei que eles vão correr. Essas grandes freadas é uma coisa constante e eu não tô afim de me machucar e nem discutir com o motorista, eu já sei o método. Acabou que todo mundo falou pra ela: "pra que foi levantar?". Realmente a mulher levantou muito antes, mas é que tá todo mundo tão acostumado que isso aconteça que o pessoal se previne, fala: "Por que que você foi levantar?"

Parece que já se assume e se aceita que apenas por deslocar-se no espaço do ônibus é provável que se caia. Fica-se sentado e depois vai-se 
direto para a porta na hora de saltar. Sem dúvida o ônibus não é um lugar para ficar passeando ou em pé sem segurar com toda a força nos ferros de apoio.

Há também os assaltos, constantemente no horizonte dos passageiros e dos rodoviários. E há de resto o ambiente com muito ruído e temperatura elevada, sobretudo pela presença do motor dianteiro, modelo antiquado e inadequado de veículo e que é o inferno sobretudo do motorista. Os veículos adaptados de chassis de caminhão, que representam a totalidade da frota de ônibus urbano comum, também não ajudam na estabilidade e contribuem para os solavancos. ${ }^{1}$

Certamente tudo isso vai provocar um certo tipo de contato, ou produzir uma moldura inarredável de qualquer contato ou diálogo que.possa ter lugar ali. Esse clima pode mesmo favorecer a interpelação agressiva - como acontece nas discussões em torno do troco, por exemplo, entre cobrador e passageiros - embora não a explique. Gera-se um clima de "cada um por si", como já assinalei em outro trabalho (Caiafa, 2002), e que tem um papel no tipo de comunicação que vai se desenvolver ali.

Todas essas características constituem o "quadro" e o "território", nos termos de Braga (1994), para as conversações em plena viagem. "Quadro" se refere ao meio material e "território" a aspectos sociais e culturais que participam do que ele denomina "dispositivos conversacionais". As regras que organizam as trocas de palavras nas diferentes sociedades funcionam na forma de dispositivos, como assinala o autor. No contexto desse ambiente, a necessidade de garantir um mínimo de tranqüilidade, tentando chegar ileso ao fim da viagem, tem certamente um papel na aproximação ou no isolamento que pode se gerar ali com estranhos, ou seja, nas possíveis situações de comunicação durante as viagens. José, usuário que havia declarado uma certa impaciência com a presença de idosos e seu direito à gratuidade, comenta:

Veja bem, eu acho a coisa justa, mas ali no coletivo você tá numa situação agressiva, é uma situação agressiva. Então, é salve-se quem puder. Sabe como é que é? Se o barco naufragar, eu vou pular. Não vai deixar primeiro as crianças, depois as mulheres, depois os idosos, depois você, entendeu, por último. Gentlemen ficam por último né? É tipo Titanic. Eu acho que seja um Titanic, um ônibus é um Titanic. Ele pode bater, pode incendiar, pode ser assaltado, pode não sei o quê mais e tal. Já tô colocando mais a situação de perigo, menos aqueles trajetos gostosos que você fica relaxado e tal. Têm trajetos tensos, né? E quando você junta muita gente, junta dentro de um ambiente pequeno, obviamente rola uma situação assim no ar agressiva, né? Você não tá numa situação confortável, você tá sentado do lado de alguém que você mal conhece, que você nunca viu na vida, pessoa que tá...pode tá com cheiro debaixo do braço, pode ser um cara que tá com as pernas abertas. Isso rola muito entre homens. Uns abrem muito a perna e você fica com a perna encolhida assim pra não roçar na perna do cara, ou então você força um 
pouco a barra, abre a tua também. Então tem essa coisa mejo agressiva sim. Então eu acho que quando o cidadão se encontra num estado mais assim agradável, mais relaxado, ele fica mais cortês, ele entende a terceira idade, ele realmente ajuda, é uma coisa assim. Agora, na situação do ônibus, numa hora de rush, numa hora de seis horas da tarde, hora de pico, rola realmente um clima tenso, entendeu? É uma tensão no ar.

Quem viaja de ônibus no Rio de Janeiro enfrenta essa tensão. É o que mostram tantas entrevistas. Em qualquer caso, o meio do ônibus dificilmente passa em branco. Nâo é um lugar onde é possivel ignorar o que nos cerca, não é um cenário passivo. E há constantemente uma comunicação que povoa esse cenário, ao menos no horizonte. Não que se gere necessariamente uma solidariedade. Ao contrário: nas situações de assalto, por exemplo, em que a violência atinge um ápice, não se pode geralmente contar com a ajuda dos outros (Caiafa, 2002). Mas a tensão não é a única marca da comunicação nas viagens. Há com certeza as impaciências, as brigas, ou mesmo a indiferença. Há a interpelação agressiva, o excesso de proximidade do assalto. E ao mesmo tempo há os "trajetos gostosos", as conversas amenas, as paqueras, os encontros fugazes dos contatos em movimento das viagens.

\section{Conversar durante as viagens}

Esses desconhecidos com que cruzamos na rua ou que encontramos no ônibus - os estranhos que não podemos localizar muito bem, ao contrário das figuras conhecidas dos meios familiares — nos fazem vislumbrar a possibilidade de outras experiências, outras vidas diferentes da nossa: outros mundos. Deleuze (1974) mostra que a presença de outrem organiza uma margem, "um fundo", "uma profundidade" em tomo dos objetos que percebo. O que não vejo é visivel para outrem e constitui todo um mundo de potencialidades e virtualidades para mim. Outrem inclui essas margens na minha experiência. Esses objetos que me escapam formam um mundo para mim e eventualmente poderiam ser percebidos por mim devido à presença de outrem. Outrem regula essas transições, tornando possivel minha experiência e ao mesmo tempo me tirando de mim mesmo. Outrem expressa mundos possíveis, reais mas não atualizados.

Em outro trabalho, mostrei como nas cidades essa experiência da alteridade se vê intensificada (Caiafa, 2003). No confronto com estranhos num espaço de outsiders em que nós mesmos nos tornamos outros, num espaço que se compõe de estrangeiros, num espaço feito de fora (Caiafa, mimeo), outrem como expressão de um mundo possivel é particularmente atuante. Deleuze observa que outrem não é sujeito nem objeto, mas um princípio que organiza o campo perceptivo, "uma estrutura". No contexto dos processos de comunicação nas cidades, chamei outrem de operador de diferenciação, porque ele me mostra outros mundos; no mesmo golpe permite minha experiência e me faz diferente de mim mesmo, me tira de mim, me distrai. 
"Outrem é um poderoso fator de distração", escreve Tournier no romance Sexta-feira ou os limbos do pacifico, que ensejou as considerações de Deleuze. Outrem desterritorializa as identidades ao nos distrair com outros mundos possíveis.

Ora, esses mundos são reais, mas não atualizados. "O mundo possível expresso existe perfeitamente, mas não existe (atualmente) fora do que o exprime" (Deleuze, 1974: p. 317). O mundo possível existe expresso pela presença de outrem. Um semblante espantado, explica Deleuze, me mostra um outro mundo espantoso, que eu não conheço. Outrem, ao "povoar o mundo de possibilidades, de fundos, de franjas, de transições", me permite experimentar um mundo de espanto ou tranqülidade, quando agora eu mesma não estou espantada nem tranqüila. Posso vir a ficar, se for verificar esse outro mundo, realizar o mundo possível. Por enquanto, "o expresso não existe fora do que o exprime", da presença de outrem. Uma fascinação das cidades é o vislumbrar desses possiveis na efervescência da variedade de outros, no confronto com a diversidade que nos apresenta outras vidas, outros mundos desconhecidos.

Precisamente, quando o outro fala - em qualquer situação de enunciação e inclusive na cidade entre estranhos ou nos ônibus - o que ocorre? Ele confere uma realidade ao possível - "uma certa realidade", escreve Deleuze. A linguagem me traz aquele estranho mundo, realiza aquele possível como um mundo que o outro me traz. A linguagem me mostra o espanto que 174 eu não conhecia - não atualizando aquele mundo, que continua existindo como possivel, mas concretizando, conferindo alguma realidade ao que outrem expressa e me traz.

A linguagem dá realidade ao estranho, a comunicação reúne para distrair os conversadores de si mesmos, para trazê-los mais perto de estranhos mundos. Essa é uma dimensão interessante da linguagem e da comunicação - conferir certa realidade a mundos possíveis - que deve ser mais ou menos ativa dependendo das situações de enunciação, ou das características do dispositivo conversacional, nos termos de Braga.

As conversações nas viagens de ônibus no Rio de Janeiro abrigam essa dimensão da concreção do possível enquanto tal, da condução do estranho na comunicação. Essa dimensão de alteridade da comunicação com certeza se realiza em algum grau e de forma específica no contexto da intensificação da experiência de outrem que os meios urbanos de ocupação coletiva produzem.

Uma das caracterísicas dos dispositivos conversacionais diz respeito aos papéis que os participantes assumem ali. Braga distingue o "papel representado", que os participantes já trazem de situações exteriores às conversas, e o "papel desempenhado", que se desenrola no contexto da conversação. Esses dois papéis "se interferem mutuamente". E há as estratégias individuais que operam com essas imposições do dispositivo. 
Podem-se gerar portanto trocas igualitárias ou hierarquizadas, em maior ou menor grau. Na situação das conversas no ônibus há uma complexidade na definição e eleição de papéis porque tende-se a não partir de uma posição definida, uma inserção clara, em contraste com o que se passa numa reunião entre conhecidos ou na pequena aldeia, onde todos podem mais facilmente se identificar. Estar entre estranhos é livrar-se em algum grau de sua identidade ou sua definição. Claro que há certas marcas que são legíveis e que acenam com um "papel representado". Por exemplo, Regina, usuária de ônibus, acha que a tendência nos ônibus é que se ceda lugar a idosos mais bem vestidos, evitando a gentileza com os mais pobres. Ali o papel representado determinou uma atitude e um tipo de comunicação. Mas essas marcas podem estar menos claras em muitos casos na situação de heterogeneidade e contágio urbanos. Há uma desinserção provisória e uma complicação maior para se definir alguém. Assim, as estratégias pessoais que, como assinala Braga, acabam por desenhar o dispositivo conversacional, podem ser mais inusitadas, talvez mais criadoras. Delineia-se uma "comunicação horizontal", em algum grau, que em outro trabalho (Caiafa, 2003) afirmei ser uma caracteristicas dos meios urbanos. Ao mesmo tempo há mais riscos. Não reconhecer é descobrir novos mundos, mas é também falhar na identificação das abordagens violentas, como no assalto ou nas discussões.

E fala-se nessas viagens de ônibus? Há alguma disposição para a conversa? A observação direta já mostra que sim. Eu mesma muitas vezes não vou calada e observo que posso freqüentemente reclamar de algo que me incomoda: as freadas, o calor. Raramente sou mal recebida pelos companheiros de viagem. A situação de desconforto e perigo (quedas, assaltos, etc.) pode tornar desejável o isolamento. Mas, por outro lado, pode incitar ao comentário, sobretudo do tipo reclamação. De toda forma, há conversas. Há usuários que relatam que sentem muito prazer em puxar assunto no ônibus. Outros não se importam ou mesmo detestam. Mas mesmo estes últimos reconhecem ali um meio em que as pessoas se falam e quem nào gosta tem que saber se esquivar. Comenta Laura, usuária das linhas 485 (Penha-General Osório) e 126 (Rodoviária-Copacabana):

Tenho que ser sincera, depende do meu estado de espírito, depende do dia. Se eu tiver em boas condições, eu vou, procuro conversar, procuro orientar da melhor forma possivel e até de repente puxar um assunto. Que isso é muito comum, você tem pessoas muito chatas que às vezes você tá cansado e tal e a pessoa fica procurando um assunto, fica procurando puxar uma conversa e você não tá com a mínima disposição.

Uma outra usuária, Cláudia, também não gosta de conversar:

- Por exemplo, falando de você, - perguntei — você conversa com as pessoas às vezes? 
- Não, muito raro.

— Ou dá informação?

- Ah, de pedir informação, se eu souber, eu dou, né? Agora, não converso, não puxo conversa não. Não gosto de ficar conversando e quando puxam conversa comigo, corto também. Não tô afim de ficar de papo furado. Tem gente que gosta ....as pessoas gostam.

— Você acha?

-É. Eu vejo muita gente assim, conversando, e você vê que é aquela conversa de ônibus.

- Como é?

— Conversa de ônibus...Só abobrinha, só abobrinha.

Você pode querer conversar e receber uma recusa. É um risco particularmente presente quando se tenta conversar com desconhecidos. Um dos problemas que surgem nessa situação é como iniciar a conversa, como puxar assunto. Essa é uma outra proposição descrita por Braga e que é aplicável à situação de conversa nas viagens de ônibus: a duração da troca e os movimentos para iniciar e terminar as conversas. Iniciar uma conversa com um estranho exige um certo ímpeto. $E$ isso não só no ônibus, mas ali se tem mais chance de deparar-se com um passageiro cansado, esgotado pela viagem dificil e sem disposição para conversar. A paquera, que também pode 176 ocorrer no ônibus, em geral se apóia numa avaliação inicial pelo olhar, antes de se partir para a conversa. $O$ término é outro ponto interessante. A conversa deve acabar quando alguém tem que saltar do ônibus. A duração é o tempo de viagem. Chegou o seu ponto e você tem que saltar. Isso gera uma situação de encontro fugaz, "à última vista", como Benjamin comenta sobre a passante do poema de Baudelaire. A beldade que passa impressiona o poeta, afeta-o, $\mathrm{e}$ se vai na multidão que a trouxe, provocando um amor "à última vista", caracteristicamente citadino (Benjamin, 1995).

É o fim abrupto. Terminou a conversa, seja qual for o ponto em que estivesse. Isso é muito freqüente e aparece em muitos relatos. São fechos do tipo: "e aí eu tive que saltar na Leopoldina". Mas.por vezes pode ser diferente:

- Ah, eu tô sempre dando informação, — observou Tatiana - sempre que alguém pergunta eu dou. E conversar também, eu já conheci várias pessoas no ônibus, principalmente um que eu até namorei ele. Ele sentou do meu lado um dia e eu me interessei assim, só que aí não rolou nada. Depois de um tempão [numa outra ocasião], eu tava sentada meio que lạ na frente e ele entrou e eu falei: "eu conheço esse cara de algum lugar". Eu fiquei meio que olhando e ele ficou sentado assim naquele ferro da saída assim, o ferro em cima do motor, ficou sentado de frente pro ônibus inteiro. Aí ele ficou me olhando e eu falei: "meu Deus eu conheço esse cara de algum lugar! Que lindo que ele é, não sei o quê." Eu tava ouvindo walkman e ele começou 
então a fazer mímica, conversando comigo e tal. Falou que me conhecia, aí ficou perguntando o que eu fazia e que eu tava ouvindo no walkman. Ai a gente começou a conversar, ali de longe. Quando chegou em Laranjeiras, eu ia descer na Santa Úrsula, que era o próximo ponto. O ônibus esvaziou e ele veio falar comigo. A gente ficou conversando e tal, ele me chamou pra dar uma volta na praia. Eu falei que não, que eu tinha que ir embora, que eu tava indo viajar, e ele falou: "pô, então a gente se vê por aí". Eu desci então na Santa Úrsula, mas assim, ai meu Deus eu queria ter ficado lá, conversado mais, não sei o quê. Aí tava indo, atravessando a passarela da Santa Ursula quando eu sinto alguma coisa correndo assim por trás e dando um salto. Era ele! A gente começou a conversar e ele falou "pô, eu saltei no ponto da frente e vim correndo pra ver se te encontrava".

Há a conversa a dois, as aproximações mais restritas, onde se inclui a paquera. Eé curioso observar que aí existe a presença de um auditório, mais ou menos atento. Mas as conversas nas viagens de ônibus podem engajar um grupo maior, e essa é uma outra caracteristica. Braga menciona também a questão do número de participantes e da posssibilidade de participar como um dos pontos a considerar no desenho do dispositivo. Nas viagens de ônibus no Rio de Janeiro, há conversas em que a admissão dos participantes tende a ser ilimitada. Alguém pode aderir, por exemplo, à resposta a um pedido de informação que não the foi dirigido diretamente. Um acontecimento no ônibus pode engajar quem o queira comentar, inclusive porque em certa medida afeta a todos, que estão ali naquele espaço a um tempo fechado e aberto - abre-se constantemente para fora, deixando entrar e sair — mas de toda forma comum.

São freqüentes também as ocasiões em que o motorista fala com a pessoa que está ao lado dele: em pé ou sentada na ciadeira individual que fica bem na dianteira do veículo, ao lado do posto do motorista. Já aconteceu muitas vezes comigo. Ou o motorista falar comigo, ou eu conseguir ouvir algum comentário dele com um passageiro perto de mim. O assunto em geral é algum acontecimento do trânsito: o motorista reclama de uma fechada, por exemplo. Ele pode também comentar algum problema que teve com o passageiro na hora de saltar. $O$ passageiro reclamou que ele não parou no ponto, ou que não encostou, parando no meio do trânsito, ou que, ao contrário, não parou para ele no meio do trânsito, onde ele queria saltar. São acontecimentos que têm lugar ali naquele canto da dianteira do carro, naquela região de contato com o motorista. Comenta Izabel:

- Pode ser uma situação qualquer. Ou o passageiro disse um desaforo pra ele, ou ele viu uma coisa na rua que fez ele gritar. Isso é muito comum, né? Eu sento muito naquela cadeirinha ali na frente, sozinha e tal. Gosto muito de sentar na frente e ele é que faz o comentário. Ele vira pra trás, parará... E você, automaticamente, você, dependendo da situação, você retribui a resposta ou não. Se você acha que a coisa pode dar um clima, desencadear algum mal 
estar, ou alguma situação mais agressiva, ou estimular a agressividade dele, pode não falar nada.

- Ele comenta coisas do trânsito?

- Comenta coisas de trânsito, ou uma coisa engraçada, ou satiriza alguma coisa do cotidiano, entendeu? Tem gente muito bem humorada. Tem, tem uma situação de motorista muito bem humorada.

\section{Algo em comum}

Sobretudo se as viagens são longas, pode haver o desejo de se dirigir a um desconhecido para matar o tempo. Comenta Patrícia:

- Você vai ficar muito tempo indo pra casa. Então, normalmente, uma viagem de ônibus demora meia hora, uma viagem demora de quarenta a quarenta e cinco minutos e às vezes você fica cansada e acaba conversando pra distrair. Sempre acontece, é normal, algumas pessoas conversarem com estranhos, não todo mundo. Às vezes, as pessoas batem papo pra esquecer e tal... Distrair, uma distração. Você bater aquele papo, sem interesse nenhum, só pra passar o tempo mais rápido, porque quando você tá conversando, passa muito mais rápido do que quando você tá parado, esperando passar ponto por ponto, né?

E conversar o quê? Quais são os temas das conversas nos ônibus? Há temas mais óbvios, que não podem deixar de comparecer, como a questão do trajeto das linhas, o lugar ónde saltar. Mas os eventos do quotidiano 178 sempre nos escapam por definição. Não seria possivel esgotar o repertório de temas dessas conversas.

- E o que em geral, você conversa com essas pessoas?

- A gente conversa negócio de bobeira mesmo - responde Jandira

- de trabalho, de hora, de chuva.

- Uma amiga tava contando um caso - comentou Laura - em que ela tava dentro de um ônibus, conheceu um menino lá dentro. Eles conversaram e foi assim uma distância pequena, mas o teor da conversa foi tão profundo, ela contou coisas assim que talvez não contasse pra pessoas que ela conhece cotidianamente, que tem uma convivência mais cotidiana e tal. E nunca mais viu. Isso é interessante. Você fica meio que poxa, então por um momento tão próximo e tão distante, entendeu?

É comum ouvir comentários sobre acontecimentos da cidade ou do mundo. Lembro-me de que, há uns dois anos atrás, quando os Estados Unidos invadiram o Afeganistão, ouvi muita coisa nos ônibus sobre isso, e eram comentários bastantes questionadores. Falei sobre isso com uma aluna, usuária de ônibus, e ela relatou que estava ouvindo muito sobre o tema também, mas o que ela ouvia parecia a réplica perfeita do Jornal Nacional. Em qualquer caso, é interessante essa oportunidade de discutir temas gerais com desconhecidos. Isso é freqüente nas viagens de ônibus. 
- Ah, falam de política - comentou Cláudia, que não gosta de conversar no ônibus. - As pessoas ficam bem politizadas, né? Mete o pau nos prefeitos, nos governadores, e é aquilo você já sabe mais ou menos assim, né? Ou é coisa de televisão também, algum papo de televisão. Defensores da moral, uma coisa assim, todo mundo muito bonzinho, muito santinho... Tem as melhores intenções, é todo mundo... Se fosse pela conversa, né? Falando sobre a vida, como tá de violência. Violência, as pessoas falam muito: "Ah, porque eu tava no ponto, é tão perigoso ficar no ponto essa hora, né, não sei quê." Sempre alguma coisa assim, em relação a perigo, a pessoa estar com medo ou não sei o quê.

- Ah, eu sempre converso - contou Patricia - Qualquer pessoa que sente do meu lado, eu puxo papo, porque eu falo muito, às vezes eu não agüento. Sempre.

- E o que você conversa?

- Normalmente, a conversa sempre se inicia com um ponto en comum das duas pessoas. Ȧs vezes, eu começo a contar: "Ai, hoje tá tão quente." Aí, se a pessoa for simpática e tal, começo a conversar. Às vezes a pessoa: "É." Aí vira pro lado e eu deixo pra lá. Só que às vezes a conversa vai rendendo. Esse domingo, eu voltei do Barra Shopping, no domingo passado, e sentou uma mulher do meu lado. Ai a gente começou a conversar, não me lembro o motivo que levou à conversa. Eu falei: "ai, eu tô tão cansada." Eu comentei em voz alta pra ver se ela falava que tava cansada também, ai ela também. A gente começou a conversar. Olha, a gente foi conversando da Barra até Madureira, foi uns quarenta minutos. Eu sei que eu sei a vida da mulher inteira. Sem querer eu consegui descobrir a vida dela inteira. Só conversando, puxando papo, ela conversa, começa... Ai, quando eu voltei lá no Barra shopping no outro domingo agora, eu fui la na loja dela e falei com ela: "Oi e ai?"

Quando falamos com desconhecidos, mesmo que um evento como o relatado acima possa se dar, abordamos muito mais comumente assuntos gerais. São temas impessoais, que não dizem respeito à nossa vida, pessoas que conhecemos, ou outros assuntos de nossa intimidade.

Gabriel Tarde distingue as conversações nas cidades pequenas e nas cidades grandes (Tarde, 1992). Nas cidades pequenas a tendência é a conversa entre conhecidos, unidos por "amizades hereditárias". O contrários se dá nas grandes cidades: pessoas que se conhecem pouco ou não se conhecem podem conversar. Em qualquer caso, escreve Tarde, as pessoas falam do que há "de mais comum e de mais conhecido" entre elas. Mas, precisamente, o que há de mais comum entre as pessoas que não se conhecem é comum também a um grande número de outras pessoas. Daí a tendência a 
discutir assuntos gerais, "idéias de interesse geral" nas conversações em grandes cidades. Nas cidades pequenas, ocorre que as pessoas em geral não dispõem, na hora de conversar, de idéias que sejam mais conhecidas, mais partilhadas, mais comuns "do que as particularidades da vida e do caráter das outras pessoas de seu conhecimento". Origina-se então "o mexerico e a maledicência".

A posição de Louis Wirth, sociólogo da Escola de Chicago, é oposta à de Tarde (Wirth, 1967). Junto a seus colegas dessa Escola, Wirth foi dos primeiros a reconhecer e tentar explicitar a especificidade das grandes metrópoles. Não lhe escapou a questão da heterogeneidade e mesmo a tendência a abrigar e mesmo produzir diferenças que o meio urbano apresenta. Ao mesmo tempo em que manteve presente em suas análise uma grande preocupação com o caráter deletério desses excessos de variação. A extrema variedade, o excesso de estímulos e a grande mobilidade dos indivíduos acabam por segmentar, fragmentar, instabilizar, criando insegurança e solidão. Suas análise parecem estipular um princípio geral sobre a interação nas cidades que deriva da observação de certos aspectos das cidades americanas. $O$ mesmo pensamento predomina na questão da comunicação. O grande número de pessoas em estado de interação produz uma comunicação elementar, primária, ou seja, "na base daquelas

180 coisas que se supõem serem comuns ou de interesse de todos". Há um empobrecimento da comunicação na situação de variação e exposição à diferença nas grandes cidades.

Para Tarde, a conversação é um grande agente de propagação do que o autor chama "imitação", força microsocial que forma a opinião, que repercute os costumes, que enfim produz as sociedades. Nesse processo, observa-se que "a progressão numérica dos interlocutores" acompanha a passagem de "temas limitados", que são de interesse de um grupo pequeno apenas, para os assuntos gerais, cada vez mais "elevados", as idéias de interesse geral que circulam nas conversações nas grandes cidades. Longe de ser empobrecedora, essa comunicação do impessoal e das idéias gerais é uma força social expressiva. A rigor, as preocupações pessoais não geram conversação. Produzem apenas "um entrelaçamento de monólogos", diz ele, recortando o termo de uma carta de Mlle de Scudéry. São os assuntos gerais que levam a conversação para além do interesse pessoal que a restringe a um grupo de conhecidos e fazem dela um agente social.

Em conexão com isso, é muito interessante o comentário de Walter Benjamin, também no contexto dos encontros nas cidades: 
As inquietações de nossa vida interior não têm, por natureza, este caráter irremediavelmene privado. Elas só o adquirem depois que se reduziram as chances dos fatos exteriores se integrarem à nossa experiência. (Benjamin, 1995: 106).

Bakhtin escreve que a enunciação se recorta de um fluxo de comunicação ininterrupta, ela é uma "fração" dessa corrente. E essa corrente de comunicação se inscreve num contexto social mais amplo, que precisa ser levado em consideração, e que ele chama de "situação extralinguistica". Além de se recortarem de uma situação complexa, as enunciações são construídas diferentemente, nos diversos contextos sociais, pela "fricção da palavra contra o meio extraverbal e contra a palavra do outro". Mas é difícil falar de fórmulas especificas da enunciação, porque essa construção responde a "particularidades fortuitas e não reiteráveis da vida corrente". É interessante que Bakhtin afirme que a enunciação formulaica tenda a ocorrer precisamente quando os participantes são familiares uns aos outros. A fórmula aparece tanto mais quanto as situações sejam regularizadas pelo uso, quanto mais existam "formas de vida em comum" estabelecidas. Estranhos que se encontram por acaso construiriam suas declarações e sua réplicas de forma menos estereotipada, como se tivessem que inventar um pouco mais já que não se conhecem, ou já que aquela situação se armou ali naquele momento e não se encontra reforçada pelo uso, não é uma situação estável, garantida pelas "fómulas da vida corrente".

Embora seja sempre o caso de particularidades fortuitas na conversação - ou seja, qualquer conversaçào implica sempre um imponderável, não encaixável numa forma fixa - a conversa com estranhos pode exigir mais invenção. Quanto mais estranheza, mais a "fricção da palavra contra a palavra" vai criar novas formas porque as situações que se armam têm sempre algum ineditismo e não sabemos bem o que esperar. Mas a presença do elemento fortuito e não reiterável ajuda aqui também a não fazer disso uma regra.

A intensificação dos efeitos de outrem no espaço de diferenças das grandes cidades pode produzir conversaçòes criadoras. Na diversidade dos temas, no risco da banalidade e da familiarização, e mesmo da violência, no imprevisivel enfim que a conversaçào quotidiana envolve, haverá efeitos criadores da circulação da palavra entre estranhos. A linguagem confere realidade a mundos possiveis. Mundos que desconhecemos, que nos vêm pela presença de outrem e que se tornam mais concretos, embora ainda não realizados, quando esse outro nos fala, quando falamos com ele. A comunicação aproxima de outrem para distrair de si. Essa dimensão de alteridade da linguagem 
e da comunicação está ativa nas conversações com desconhecidos nas cidades, mesmo que as ocasiões sejam muito variadas, que haja muitos fracassos dessa criatividade e que, afinal, não possamos estabelecer uma fórmula, aqui também, para a linguagem fortuita, impalpável do quotidiano.

No meio tenso das viagens de ônibus, o isolamento, o namoro, as aproximações violentas, e ainda as conversas de ocasião preenchem um quotidiano muito interessante. Em nossos ônibus, a diversidade urbana não parece ser, em mais de um sentido, muda. Sobretudo quando as vozes se elevam sobre um fundo de ruido e cansaço.

\section{Bibliografia}

Bakhtin, Mikhail (V. N. Volochinov). Marxismo e Filosofia da Linguagem. São Paulo: Editora Hucitec, Annablume, 2002.

Benjamin, Walter. "Sobre alguns temas em Baudelaire". Charles Bauderaire: um lírico no auge do capitalismo. Obras escolhidas III. São Paulo: Brasiliense, 1995.

Braga, José Luiz. "Sobre a conversação". Brasil: comunicação, cultura e politica. Antonio Fausto Neto, José Luiz Braga e Sérgio Dayrell Porto (orgs). Rio de Janeiro: Diadorim. 1994.

Braudel, Fernand. Civilisation matérielle, économie et capitalisme, XVeXVIIIe siècle, tome 3. Paris, Armand Colin, 1979.

Caiafa, Janice. Jornadas urbanas: exclusão, trabalho e subjetividade nas vaigens de onibus na cidade do Rio de Janeiro. Rio de Janeiro: FGV Editora, 2002.

"Comunicação e Diferença nas Cidades". Lugar Comum. Estudos de midia, cultura e democracia, $\mathrm{n}^{\circ}$ 18, novembro 2002-junho 2003.

"Uma aventura própria das cidades". Trabalho apresentado no Seminário Aberto "O Trabalho da Multidão". Museu da República, Rio de Janeiro, outubro de 2002. Coletânea do evento, e-papers (no prelo). Mimeo. - Fast trips and foreignnesses: an anthropological study of Hispanic women as other in American society. Tese de Doutorado. Cornell University, Ithaca, NY, EUA, 1991.

Deleuze, Gilles. "Michel Tournier e o Mundo sem Outrem". A Lógica do Sentido. São Paulo: Perspectiva, 1974.

Mumford, Lewis. The City in History. New York: Harcout, Brace \& World, Inc, 1961.

Tarde, Gabriel. A opinião e as Massas. São Paulo: Martins Fones, 1992. 
Wirth, Louis. "O urbanismo como modo de vida". O fenômeno Urbano. Otávio Guilherme Velho (org.). Rio de Janeiro, Zahar Edidtores, 1967.

\section{Notas}

Trabalho Apresentado no $12^{\circ}$ Encontro Anual da $A$ ssociação Nacional dos Programas de Pós-Graduação $\mathrm{cm}$ Comunicaçào (Compós 2003).

' Para uma discussão do ambiente matcrial do ônibus $\mathrm{c}$ suas repercussões nas viagens e no trabalho do rodoviário, vcr Caiafa (2002), sobretudo o capítulo "Uma arquitetura itinerante". 
184

\section{Palavras-chave}

1. Transporte coletivo

2. Processos de comunicação

3. Conversação

4. Cidade 